Research Article

\title{
Ordering Policy of Two-Stage Newsvendor Model for Fresh Retailer under RFID Investment
}

\begin{abstract}
Na Fu ii
Tianjin Agricultural University, Tianjin, China

Correspondence should be addressed to Na Fu; scarlett_fn@126.com

Received 24 February 2021; Revised 4 April 2021; Accepted 11 May 2021; Published 24 May 2021

Academic Editor: Junhai Ma

Copyright (c) $2021 \mathrm{Na} \mathrm{Fu}$. This is an open access article distributed under the Creative Commons Attribution License, which permits unrestricted use, distribution, and reproduction in any medium, provided the original work is properly cited.

Fresh products have a strong dependence on time and a large loss rate in the circulation process. Applying RFID technology to the supply chain of fresh products, through the real-time tracking technology, can not only reduce the products' time dependence but also realize the second order within the whole sales period. This paper takes a two-echelon fresh supply chain of a single fresh retailer as the research object, constructs a two-stage Newsvendor model with or without RFID technology, compares the difference in profits, and provides decision-making reference for fresh retailers whether to invest in RFID or not.
\end{abstract}

\section{Introduction}

In 2020, the operating scale of China's fresh market reached US\$38.35 billion, with a year-to-year growth of $48.9 \%$. The growth rate is far higher than the previous. However, the fresh retailers are experiencing unprecedented ice and water. On the one hand, many retailers kept losing money until bankruptcy. For example, in October 2020, Yiguo Fresh, China's first fresh e-commerce company, was still unable to make up for its losses after total financing of more than US\$100 million and had to declare bankruptcy. On the other hand, the capital keeps pouring in. For example, another fresh food giant, Miss Fresh, completed a new round of US\$31 million financing in December 2020, and the total amount of financing exceeded US\$216 million! Why do fresh retailers keep closing, but there is always a continuous influx of new capital?

This is because fresh products have the characteristics of high loss rate, short shelf life, strong time dependence, long lead time, and uncertain demand. These will affect fresh retailers' profits and lead to fresh business in high risk. However, fresh products also have the characteristics of high user stickiness and high repeat purchasing rate, which can bring sustained consumption, attention, and stable popularity to retailers. Therefore, the capital investor has both hatred and love for fresh investment: hatred for its serious imbalance between input and output and love for its large market potential. There is a saying in the fresh industry that says, "do fresh to seek death, do not do fresh to wait for death."

The emerging Internet of Things (IoT) technology is transforming the fresh business by significantly improving the efficiency of fresh food logistics. For example, using the radio frequency identification (RFID) technology is effective in resolving the time/temperature control issue, which is critical to loss rate control in fresh food logistics (Montanari, 2008 [1]; Fu et al., 2019 [2]; Wu and Ma, 2020 [3]).

Many fresh retailers apply RFID technology to ordering and inventory management. RFID technology can improve the fresh retailers' profits in the following aspects. Firstly, real-time detecting temperature, humidity, and other production environments effectively control product quality, reduce loss rate, and reduce fresh products' time dependence. Secondly, monitoring manual operation and other circulation environments seamlessly connects upstream and downstream enterprises, accelerates the links between logistics procedures, improves transportation efficiency, shortens the circulation cycle and lead time, and realizes the second order. Thirdly, gathering and sharing data enhance the demand forecasting accuracy, reduce the risk of demand uncertainty, and improve order error and other issues.

However, the application of RFID technology requires a large amount of input, which seriously hinders the RFID 
application. Through the collection and analysis of sample data of South African retailers, Brown and Russell [4] found that although the retailers showed strong interest in RFID technology, the high initial investment greatly hindered the wide application of RFID. Costa et al. [5] also pointed out that although RFID has many advantages, its practical application is still subject to economic and technical limitations in cost standards, data processing, and other aspects.

Therefore, this paper takes a two-echelon fresh supply chain of a single retailer as the research object, constructs a two ordering opportunities' model with or without RFID, compares the difference in profit, and provides important managerial insights for fresh retailers whether to invest in RFID.

The remainder of the paper is organized as follows. In Section 2, we review the related literature. In Section 3, we construct a two-echelon fresh supply chain with or without RFID. In Section 4, we use sensitivity and numerical analysis to further analyze and prove the conclusions of the model. In Section 5, we conclude the paper and propose future research directions.

\section{Literature Review}

The research related to this paper mainly involves three categories: the newsvendor model with two ordering opportunities, the uncertainty and complex analysis of supply chain, and the application of RFID technology in fresh products supply chain. Therefore, our literature review mainly focuses on these three aspects.

\subsection{The Newsvendor Model with Two Ordering Opportunities.} There is a lot of research on newsvendor model with two ordering opportunities. Some focus only on the retailers while others analyze the problem in the context of a manufacturer-retailer supply chain.

Research focuses only on the retailers' strategies. Gurnani and Tang [6] determined the optimal ordering policy for a retailer, where the unit cost was known for the first order and random for the second order. Yan et al. [7] studied a model under a service-level constraint and found that the optimal expected profit is monotone in respect of the target service level. Ma et al. [8] considered a fashion supply chain characterized by a long lead time and a short selling season, derived the retailer's optimal ordering decisions, and analyzed the monotonicity behaviours of the critical market signal, the optimal first-stage order quantity, and the optimal expected payoff with respect to the penalty coefficient. $\mathrm{Li}$ et al. [9] examined the impact of a second procurement opportunity on the inventory management of products with short selling seasons. By casting the models as sequential decision-making problems, they reduced the optimization problems into sequential and embedded searches for the concerned decision variables. Khouja and Zhou [10] found that the off-price retailer is more likely to use the first ordering opportunity under limited supply even when there is a premium for the newness of the second order. Herbon et al. [11] assumed that the retailer has two opportunities for receiving shipment and presented an extensive numerical example that compares the suggested strategy to three alternative strategies, and they concluded that price postponement and responsiveness to demand changes can each reduce leftovers and lost sales as well as substantially increasing expected profit.

Research dealing with the relationships between manufacturer and retailer frequently focuses on coordinating the supply chain. Tiwari et al. [12] assumed two ordering opportunities from two nonidentical and unreliable suppliers with random yield and indicated that a retailer should focus on increasing the minimum order guarantee from a first stage supplier to reduce its total supply chain cost. Zhou and Wang [13] proposed an improved revenue-sharing contract that can realize the perfect coordination of a two-echelon supply chain with two ordering opportunities. On this basis, Wang et al. [14] quantified the impact of the multiordering strategy on the newsvendor's expected profit and risk exposure by comparing the multiordering and single-ordering models. Jain et al. [15] developed a model in which the retailer can place multiple orders during the selling season and the orders can be triggered anytime and found that the optimal retailer policy can sometimes cause large demand variation for the supplier, resulting in lower supplier profit. In centralized settings, this may even result in lower system profit than some naïve retailer heuristics, creating inefficiency in the supply chain. Wee and Wang [16] developed a problem where the retailer has a second replenishment opportunity to order an option quantity from the manufacturer to fulfil its backorders and showed that the integrated system has a greater profit than the decentralized system irrespective of the back-ordering rate. Kelei et al. [17] investigated two types of procurement strategies with two ordering opportunities and found that, under both types of strategies, the retailer's procurement follows a "threshold" principle. Counterintuitively, a lower mean value of the emergency procurement price is not always beneficial to the retailer. A higher market demand variability could be beneficial to the supplier.

\subsection{The Uncertainty and Complex Analysis of Supply Chain.} Seasonal change, technology upgrade or policy shocks, drastic output, and other uncertainty factors all can cause the market's complex fluctuations; therefore, the uncertainty and complex of supply chain have aroused wide attention in academics. Ma and Guo [18] analyzed the dynamics of a duopoly Cournot game model with players having different adjustment mechanisms and expectations. On this basis, $\mathrm{Ma}$ and Wang [19] further analyzed the influences of decision parameters on the complex nonlinear dynamics behaviors of the two models by comparing parameter basin plots and showed that, with the improvement of retailer's competitive position, the CLSC system will be easier to enter into chaos. And the larger multiproduct substitution level is advantageous to promote the stability of the market ( $\mathrm{Ma}$ and $\mathrm{Wu}$, 2014 [20]; Wu and Ma [21]). Naimazada and Tramontana [22] built a triopoly game model with nonlinear demand function and found that when Nash equilibrium lost 
stability, the competitive market entered into complex dynamics that were characterized by random chaotic fluctuations. Ma and Xie [23] found that the system stability will be easier to maintain with asymmetric channel power and the market will be much easier to fall into chaos with symmetric channel power. Ma and Hao [24] analyzed the source of system instability in each link and the impact of relevant parameters on system stability and profitability and found that chaos occurs with the increase in the remanufacturer's sensitivity. Hommens et al. [25] considered a model of evolutionary competition between adjustment processes in the Cournot oligopoly model and investigated the effect of increasing the number of firms. They found that a sufficient increase in the number of firms in the market tends to make the Cournot-Nash equilibrium unstable. Wu and $\mathrm{Ma}$ [26] found that the increase in output adjustment speeds of main chain enterprise can break equilibrium, cause flip fluctuation in the main chain market, and lead to the market crash in epiphytic market. Ahmad and Marina [27] analyzed the existence of equilibrium for an exchange economy evolutionary model. Askar et al. [28] investigated the Nash equilibrium and chaos fluctuations in a game model constructed by three competitive firms, and the firm's preference was derived from the constant elasticity of substitution (CES) production function.

On this basis, some researchers took household appliance and automobile supply chain system as examples, respectively, and studied the effect of price adjusting on the profits and system's stability (Lou and Ma, 2018 [29]; Ma and Sun, 2018 [30]; Bao et al., 2020 [31]; Ma et al., 2021 [32]). Ma and Sun [30] discussed the effect of the system instability on the average profit of the two sides with 3D and 4D average profit graphs. Peng et al. [33] constructed a 3D Hotelling price discrete dynamic model, analyzed the influence of important parameters on the model equilibrium, and described the chaotic behavior of the system through numerical simulation. Zhou and Wang [34] constructed a profit-maximizing game model for R\&D competition, analyzed the stability of Nash equilibrium, and found that highly efficient innovative companies can benefit from the chaos. Ma et al. [35] aimed to research the impacts of pricing time on profitability and stability, and they found that, with the adjustment of parameters, the state of the system is switched between stability and instability. Xie et al. [36] found that when the seller's bargaining power is relatively high and can control the uncertain yield, the buyback contract is sufficient to coordinate the supply chain. Garmani et al. [37] analyzed the chaos phenomenon and the balance of the game and found that the appropriate method can be used to control the chaos. $\mathrm{Xu}$ and $\mathrm{Ma}$ [38] found that chaos is not just an unfavorable phenomenon for everyone; for the players with risk preference, chaos might be a good ladder to achieve high returns. For those risk aversion players, they also provide a controlling method to control it back to a stable state.

\subsection{The Application of RFID Technology in Fresh Product} Supply Chain. There are types of research on RFID application in the supply chain, which mainly focus on real-time tracking, gathering information, shortening circulation time, etc. For example, Szmerekovsky and Zhang [39] studied the influence on manufacturers and retailers of attaching RFID at the item level in a VMI system and found that RFID can shorten the supply lead time and improve ordering accuracy.

To explore the out-of-stock business case for RFID, Walmart commissioned a study to measure the impact of the technology on out-of-stocks. The research showed that in the test stores RFID-tagged items experienced fewer stock-outs than nontagged items, and out-of-stocks were reduced by 21\% more than in the control stores (Goyal et al. [40]). Furthermore, through two different field experiments, Hardgrave et al. [41] indicated a significant decrease in inventory record inaccuracy of approximately $26 \%$ due to RFID-enabled visibility. Similar studies have also been done by other scholars ((Rekik et al., 2009 [42]; Heese, 2010 [43]; Camdereli and Swaminathan, 2010 [44]; Yan et al., 2015 [45]; and so on). They all pointed out that RFID can remedy substantial discrepancies between inventory quantities recorded in the system and stocks truly available to customers, eliminate the problem of inventory record inaccuracy and misplacement, and reduce the error rate and loss of inventory.

Fewer researches focus on RFID application in the fresh product supply chain. One part studied RFID effect on controlling fresh product quality, reducing fresh products' time dependence and loss rate of fresh products in circulation. Hong et al. [46] discussed the applications of RFID to a food traceability system, pointing out that RFID can capture data about ingredients, manufacture, and dates certain and provide a transparent manner to supply chain participants and consumers. Ruiz-Garcia and Lunadei [47] pointed that RFID offers vast opportunities for research, development, and innovation in agriculture, gave a comprehensive view of current applications and new possibilities, and also explained the limitations and challenges of RFID. Costa et al. [5] summarized the literature on RFID application in agriculture, pointed out that RFID can provide appealing opportunities to improve the management of information flow within the supply chain and security in the agrifood sector, and introduced the advantages and limitations of this technology in agriculture. Kumari et al. [48] studied the possible conflicts in the information reading process, information security and privacy issues, cost considerations, and the implementation of RFID standards.

The other part focused on the cost of RFID and its influence on profit. Camdereli and Swaminathan [44] studied both centralized and decentralized cases, identified the conditions to coordinate the supply chain under the implementation of RFID, and found that the incentives of the parties for investing in the technology are not perfectly aligned with the existence of the fixed cost of investment. Gaukler et al. [49] examined both the case of a dominant manufacturer and the case of a dominant retailer, and they analyzed the results of an introduction of RFID to such a supply chain depending on these market power characteristics. Yan et al. [50] studied the impact of RFID application and supply chain coordination on the triple bottom line of sustainable development including corporate profit, social responsibility, and environmental responsibility that were analyzed. Li et al. [51] considered a supply chain consisting 
of one supplier and one retailer who jointly invest RFID by considering their demands and inventory. They found that the retail supply chain can be coordinated perfectly under the RCS contract when the thresholds of the revenue/costsharing rates are set appropriately.

In summary, the traditional model with two ordering opportunities only emphasizes the uncertainty of demand and seldom considers the uncertainty of supply. At the same time, the research on the application of RFID technology is mostly based on the traditional newsvendor model, and few studies put RFID into the model with two ordering opportunities. One of the characteristics of fresh products is the uncertainty of supply, and RFID technology can reduce this uncertainty, while the second ordering can reduce the uncertainty of demand. The innovation of this paper is to link RFID and the second order together, considering that the double uncertainty can be reduced and the impact of RFID investment on the retailer's order decision and profit, as well as the critical conditions of whether to choose RFID investment, which has a strong theoretical significance.

\section{Model Construction}

3.1. Parameter Meaningand ModelingIdea. In this paper, the subscript $r$ is used to indicate the case of introducing RFID, $Q$ represents the ordering quantity without introducing RFID, and $Q_{1}$ and $Q_{2}$ represent the first and second ordering quantity with RFID investment, respectively. The meanings of other symbols are shown in Table 1.

Since the market demand of fresh product is uncertain, it is represented by the random variable $X$. It follows a normal distribution where the expectation is $\mu$ and the standard deviation is $\sigma$. The probability density function and the distribution function are $f(x)$ and $F(x)$, respectively.

$X_{1}$ and $X_{2}$ represent the market demand before and after the arrival of second ordering with RFID. They all conform to normal distributions whose expectations are $\mu_{1}$ and $\mu_{2}$ and the standard deviations are $\sigma_{1}$ and $\sigma_{2}$ respectively. Their probability density functions are $f_{1}\left(x_{1}\right)$ and $f_{2}\left(x_{2}\right)$; the distribution functions are $F_{1}\left(x_{1}\right)$ and $F_{2}\left(x_{2}\right)$. After the introduction of RFID, the demand forecast of the second order is more accurate, so the variance of demand forecast $\sigma_{2}$ is smaller, that is, $\sigma_{1}>\sigma_{2}$. According to the additivity of normal distribution, $\mu_{1}+\mu_{2}=\mu$, $\sigma_{1}+\sigma_{2}=\sigma$.

Although China's fresh Market is very large, it is scattered and chaotic. Each fresh retailer occupies a very small share and has no control over the upstream and downstream. Therefore, the fresh retailer can only passively accept the wholesale price $w$ of the supplier and sell product at an exogenous retail price $p$.

Because the fresh product has a certain loss rate, the actual arrived quantity is not exactly equal to the ordering quantity. $\theta$ is used to represent the ratio of the arrived quantity to the ordering quantity without RFID.

$$
\theta=e^{-\lambda t}
$$

where $t$ represents the procurement lead time. $\lambda$ denotes the time dependence of fresh product, and the greater the time dependent, the greater the $\lambda$.
TABLE 1: The meanings of parameters and symbols.

$X$ : random demand

$f(x)$ : probability density function of $x$

$F(x)$ : distribution function of $x$

$T$ : sales period

$t$ : lead time without RFID

$\lambda$ : time dependence without RFID

$w$ : unit procurement price

$c_{s}$ : unit shortage cost

$c_{d}$ : unit disposal cost

$c_{h}$ : unit holding cost

$c_{b}$ : unit delay cost

$X_{1}$ : random demand before the second order is reached

$X_{2}$ : random demand after the second order is reached

$p$ : market retail price of fresh product

$\tau$ : second order product arrival time

$t_{r}$ : lead time with RFID

$\lambda_{r}$ : time dependence with RFID

$\theta$ : ratio of arrived quantity to the ordering quantity without RFID

$\theta_{r}$ : ratio of arrived quantity to the ordering quantity with RFID

$c_{r}$ : unit RFID cost

$\pi$ : profit of fresh retailer without RFID investment

$\pi_{r}$ : profit of fresh retailer with RFID investment

$(\partial \theta / \partial t)=-\lambda e^{-\lambda t}<0$ indicates that the longer the lead time, the higher the loss rate. When the lead time is zero, the loss rate is zero.

$(\partial \theta / \partial \lambda)=-t e^{-\lambda t}<0$ indicates that the greater the time dependence, the higher the loss rate.

$\theta_{r}$ represents the ratio of the arrived quantity to the ordering quantity without RFID.

$$
\theta_{r}=e^{-\lambda_{r} t_{r}}
$$

This is because RFID technology can improve the automation level of fresh supply chain, reduce the operation time of logistics and manpower, shorten each link time of circulation, and shorten the lead time of fresh product, $t_{r}<t$. At the same time, RFID technology can monitor the circulation environment of fresh product such as temperature and humidity in real time, reduce their losses in the circulation process, and reduce the time dependence of fresh product, namely, $\lambda_{r}<\lambda$. Of course, the introduction of RFID technology will also generate cost, assuming unit RFID cost is $c_{r}$.

3.2. Basic Model without RFID. Suppose that the retailer's ordering quantity is $Q$ at time 0 . Due to the loss in circulation, the actual quantity arriving at the time $t$ is only $\theta Q$. And they will be sold in the wholesales period $T$, as shown in Figure 1. When the market demand is greater than the actual arrival quantity, the retailer bears the unit shortage cost $c_{s}$. When the actual arrival quantity is greater than the actual market demand, the retailer should dispose of the unsold fresh product, and the unit disposal cost is $c_{d}$.

According to the above description, without RFID, the expected profit of the fresh retailer is 


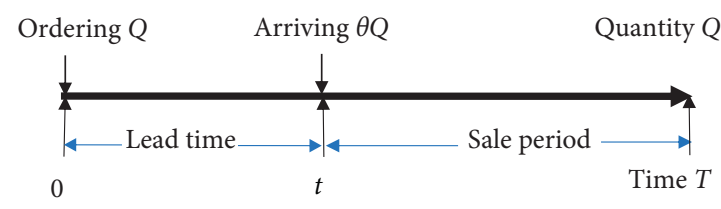

FIgURE 1: Model timeline without RFID.

$\pi=p * \min \{\theta Q, X\}-c_{s} * \max \{X-\theta Q\}-c_{d} * \max \{\theta Q-X, 0\}-w Q$

According to the basic algorithm of newsvendor model, taking the first and second derivatives of (3) Proposition 1 can be obtained. See Appendix for the specific proof process.

Proposition 1. Without RFID investment, there is a unique optimal ordering quantity $Q^{*}$, which maximizes the profit of fresh retailer and satisfies

$$
\int_{0}^{\theta Q^{*}} f(x) \mathrm{d} x=\frac{\left(p+c_{s}\right) \theta-w}{\left(p+c_{s}+c_{d}\right) \theta} .
$$

Substitute (4) into (3); the optimal profit can be obtained:

$$
\pi^{*}=\left(p+c_{s}+c_{d}\right) \int_{0}^{\theta Q^{*}} x f(x) \mathrm{d} x-c_{s} \mu .
$$

3.3. Extended Model with RFID. After the introduction of RFID technology, the fresh retailer can make a second order within the lead time, and the timeline is shown in Figure 2. When the market demand from time 0 to $t_{r}$ is less than $\theta_{r} Q_{1}$, there will be a holding $\operatorname{cost} c_{h}$ per unit of product. When the market demand from time 0 to $t_{r}$ is greater than $\theta_{r} Q_{1}$, there will be an order delay cost $c_{b}$ per unit of product.

According to the above description, with RFID, the expected profit of the fresh retailer is

$$
\begin{aligned}
\pi_{r}= & p * \min \left\{\theta_{r}\left(Q_{1}+Q_{2}\right), X\right\}-c_{h} * \max \left\{\theta_{r} Q_{1}-X_{1}, 0\right\}-c_{b} * \max \left\{X_{1}-\theta_{r} Q_{1}, 0\right\} \\
& -c_{s} * \max \left\{X-\theta_{r}\left(Q_{1}+Q_{2}\right), 0\right\}-c_{d} * \max \left\{\theta_{r}\left(Q_{1}+Q_{2}\right)-X, 0\right\}-\left(w+c_{r}\right)\left(Q_{1}+Q_{2}\right)
\end{aligned}
$$

Taking the first and second derivatives of (6), Proposition 2 can be obtained. See Appendix for the specific proof process.
Proposition 2. With the RFID investment, there is a unique optimal ordering quantity $\left(Q_{1}^{*}, Q_{2}^{*}\right)$ that can realize fresh retailer profit maximum, and $\left(Q_{1}^{*}, Q_{2}^{*}\right)$ satisfies the following equation:

$$
\begin{gathered}
\int_{0}^{\theta_{r}\left(Q_{1}^{*}+Q_{2}^{*}\right)} f(x) \mathrm{d} x=\frac{\left(p+c_{s}\right) \theta_{r}-\left(w+c_{r}\right)}{\left(p+c_{s}+c_{d}\right) \theta_{r}}, \\
\left(p+c_{s}+c_{d}\right) \int_{0}^{\theta_{r}\left(Q_{1}^{*}+Q_{2}^{*}\right)} f(x) \mathrm{d} x+\left(c_{h}+c_{b}\right) \int_{0}^{\theta_{r} Q_{1}^{*}} f_{1}\left(x_{1}\right) \mathrm{d} x_{1}=\frac{1}{\theta_{r}}\left(\left(p+c_{s}\right) \theta_{r}+c_{b} \theta_{r}-\left(w+c_{r}\right)\right) .
\end{gathered}
$$

According to Proposition 2, by subtract (7) from (8), Corollary 1 can be obtained.

Corollary 1. With RFID investment, the first optimal ordering quantity $Q_{1}^{*}$ satisfies

$$
\left(c_{h}+c_{b}\right) \int_{0}^{\theta_{r} Q_{1}^{*}} f_{1}\left(x_{1}\right) \mathrm{d} x_{1}=c_{b}
$$

According to Corollary 1, after investing in RFID, the first optimal ordering quantity is only related to the holding $\operatorname{cost} c_{h}$ and delay cost $c_{b}$. It has nothing to do with the unit procurement cost $w$, shortage cost $c_{s}$, disposal cost $c_{d}$, and RFID input $c_{r}$.

By substituting (7) into (6), the optimal profit of the fresh retailer with RFID is obtained:

$$
\pi_{r}^{*}=\left(p+c_{s}+c_{d}\right) \int_{0}^{\theta_{r}\left(Q_{1}+Q_{2}\right)} x f(x) \mathrm{d} x+\left(c_{h}+c_{b}\right) \int_{0}^{\theta_{r} Q_{1}} x_{1} f_{1}\left(x_{1}\right) \mathrm{d} x_{1}-\left(c_{b} \mu_{1}+c_{s} \mu\right)
$$




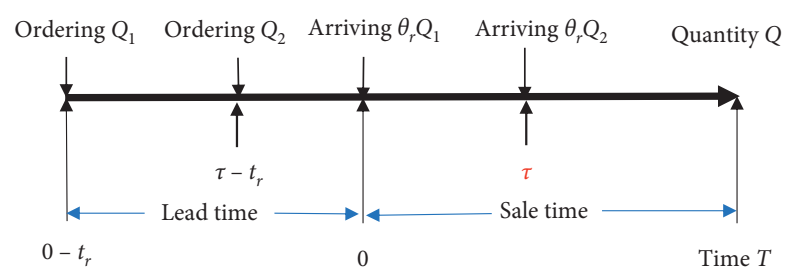

FIgURE 2: Model timeline with RFID.

3.4. Two Model Comparison. According to Propositions 1

and 2 and by assumption,

$$
\begin{aligned}
A & =\int_{0}^{\theta Q^{*}} f(x) \mathrm{d} x=\frac{\left(p+c_{s}\right) \theta-w}{\left(p+c_{s}+c_{d}\right) \theta}=\frac{\left(p+c_{s}\right)-(w / \theta)}{\left(p+c_{s}+c_{d}\right)} \\
B & =\int_{0}^{\theta_{r}\left(Q_{1}^{*}+Q_{2}^{*}\right)} f(x) \mathrm{d} x=\frac{\left(p+c_{s}\right) \theta_{r}-\left(w+c_{r}\right)}{\left(p+c_{s}+c_{d}\right) \theta_{r}}=\frac{\left(p+c_{s}\right)-\left(\left(w+c_{r}\right) / \theta_{r}\right)}{\left(p+c_{s}+c_{d}\right)} \\
\varphi(q) & =\int_{0}^{q} f(x) \mathrm{d} x \\
q_{1} & =\theta Q^{*} \\
q_{2} & =\theta_{r}\left(Q_{1}^{*}+Q_{2}^{*}\right) .
\end{aligned}
$$

Then we can get

$$
A-B=\varphi\left(q_{1}\right)-\varphi\left(q_{2}\right)=\frac{\left(p+c_{s}\right) \theta-w}{\left(p+c_{s}+c_{d}\right) \theta}-\frac{\left(p+c_{s}\right) \theta_{r}-\left(w+c_{r}\right)}{\left(p+c_{s}+c_{d}\right) \theta_{r}}=\frac{\left(w+c_{r}\right) \theta-w \theta_{r}}{\theta \theta_{r}} .
$$

When $c_{r}>\left(w\left(\theta_{r}-\theta\right) / \theta\right), A>B$, because $\varphi(q)$ is an inIn the same way, crement function of $q$, then $\theta Q^{*}>\theta_{r}\left(Q_{1}^{*}+Q_{2}^{*}\right)$, and because $\theta<\theta_{r}$, therefore, $Q^{*}>\left(Q_{1}^{*}+Q_{2}^{*}\right)$.

$$
\Delta \pi=\pi_{r}-\pi=\left(p+c_{s}+c_{d}\right) \int_{\theta Q^{*}}^{\theta_{r}\left(Q_{1}+Q_{2}\right)} x f(x) \mathrm{d} x+\left(c_{h}+c_{b}\right) \int_{0}^{\theta_{r} Q_{1}} x_{1} f_{1}\left(x_{1}\right) \mathrm{d} x_{1}-c_{b} \mu_{1} .
$$

According to (9),

$$
\left(c_{h}+c_{b}\right) \int_{0}^{\theta_{r} Q_{1}} x_{1} f_{1}\left(x_{1}\right) \mathrm{d} x_{1}-b \mu_{1}>0
$$

So, whether $\Delta \pi$ is greater than zero depends on the relationship between $Q^{*}$ and $\theta_{r}\left(Q_{1}^{*}+Q_{2}^{*}\right)$. Then Corollary 2 can be obtained.

Corollary 2. When $c_{r}>\left(w\left(\theta_{r}-\theta\right) / \theta\right), Q^{*}>\left(Q_{1}^{*}+Q_{2}^{*}\right)$, and $\pi^{*}>\pi_{r}^{*}$.

According to Corollary 2, when the unit cost of RFID technology exceeds a certain value, that is, $c_{r}>\left(w\left(\theta_{r}-\theta\right) / \theta\right)$, the optimal ordering quantity and profit without RFID are all greater than those with RFID. It can also be understood that the degree of reduction of loss rate caused by RFID is less than a certain value $\left(\theta / \theta_{r}\right)>\left(w / w+c_{r}\right)$; that is, when RFID technology does not significantly improve the loss rate of fresh product, the fresh retailer should not invest in RFID.

\section{Sensitivity Analysis and Numerical Examples}

4.1. Sensitivity Analysis. First, we analyze the case without RFID. According to Proposition 1, Corollary 3 can be obtained. 


\section{Corollary 3. Without RFID investment,}

(i) The optimal ordering quantity $Q^{*}$ increases with shortage cost $c_{s}$ and decreases with procurement cost $w$ and disposal cost $c_{d}$.

(ii) When $w<\theta^{2}\left(p+c_{s}+c_{d}\right) Q^{*} f\left(\theta Q^{*}\right)$, the optimal ordering quantity $Q^{*}$ decreases with the loss rate $(1-\theta)$.

Corollary 3 shows the optimal ordering quantity is not a monotone function of the loss rate. Their relationship depends on the wholesale price. A higher wholesale price means a higher cost lost. Therefore, when the wholesale price is high, the profit loss caused by it exceeds the impact of outof-stock. Fresh retailer prefers to bear the loss of out-of-stock rather than order. On the contrary, when the wholesale price is lower, even if the loss rate is higher, the reduced profit caused by them will be smaller. Therefore, the fresh retailer is willing to increase the ordering quantity to avoid the profit loss caused by shortage.

According to the optimal profit equation (5) without RFID, Corollary 4 can be obtained.

Corollary 4. Without RFID investment, the optimal profit $\pi^{*}$ decreases with the loss rate $v(1-\theta)$, shortage cost $q 12 c_{s}$, and product time dependence $\lambda$.

Corollary 4 shows that the optimal profit is a monotonically reduction function of the loss rate. This is because no matter what other factors affect, an increase in loss rate will lead to a decrease in profit. Similarly, the increase of shortage cost and product time dependence will also lead to the decrease of the optimal profit.

Similar to analysis without RFID investment, according to Proposition 2 and Corollary 1, Corollary 5 can be obtained. And according to the optimal profit equation (10) with RFID, Corollary 6 can be obtained.

\section{Corollary 5. With RFID investment,}

(i) The first optimal ordering quantity $Q_{1}^{*}$ decreases with unit holding cost $m k c_{h}$ and increases with the unit delay cost $T G c_{b}$.

(ii) The optimal total ordering quantity $6\left(Q_{1}^{*}+Q_{2}^{*}\right)$ decreases with the unit procurement cost $w$, the holding cost $c_{h}$, the RFID cost $c_{r}$, the loss rate $\left(1-\theta_{r}\right)$, and the product lead time $t_{r}$ and increases with the lead time $t_{r}$.

Corollary 6. With RFID investment, the optimal profit $\pi_{r}^{*}$ decreases as the loss rate $\left(1-\theta_{r}\right)$, the lead time $t_{r}$, and the product time dependence $\lambda$.

4.2. Numerical Examples. Taking kiwifruit sales as an example, assume that the selling price is $p=10$, the procurement cost is $w=3$, the shortage cost is $c_{s}=7$, the dispose cost is $c_{d}=1$, the selling period is $T=20$, the total market demand in the sales period $X$ follows the normal distribution of expectation $\mu=500$, and the variance is $\sigma=121$. We analyze the difference between RFID and without RFID.

In the case without RFID, assume the lead time $t=7$ and product time dependence $\lambda=0.01$. By calculation, $Q^{*}=544$, $\pi^{*}=3336.01$. When each parameter changes, the optimal ordering quantity and profit change accordingly. The specific changes are shown in Tables 2 and 3.

From lines 1 to 3 in Table 2, it can be found that the increase of the unit shortage cost $c_{s}$, the procurement cost $w$, and disposal cost $c_{d}$ will lead to an increase in the optimal ordering quantity and a decrease in the profit. Line 4 shows that an increase in the product time dependence $\lambda$ leads to an increase in the optimal ordering quantity but a decrease in the profit. These results are consistent with Corollaries 3 and 4. And according to lines 5 and 6 , it can be found that the change of the mean has a large influence on both the optimal ordering quantity and profit, but the variance has relatively little effect on both.

According to Table 3, it can be found that a lengthening in the lead time $t_{r}$ will lead to an increase in the ordering quantity, but it will lead to a decrease in the optimal profit. Because the lengthening of the lead time will increase the fresh product's loss rate, the retailer will increase the ordering quantity for the sake of stock adequacy and lead to the decrease of the optimal profit.

Because RFID technology can reduce the product time dependence of fresh products and shorten the lead time of products. Therefore, after introduction of RFID, we assumed that $\lambda_{r}=0.005, t_{r}=5$. And we assumed the unit RFID cost $c_{r}=0.1$, the unit holding cost $c_{h}=0.5$, the unit order delay cost $c_{b}=0.8$, and the second order arrival time $\tau=3$.

The later the second order starts, the higher the accuracy of market demand forecast and the smaller the variance of market demand will be. At the same time, the longer the market demand needs to be satisfied by the first order, the worse the prediction accuracy and the greater the variance will be. According to the additivity of normal distribution variance, $\sigma_{1}^{2}+\sigma_{2}^{2}=\sigma^{2}$. We can come to the same conclusion: the smaller the market demand variance of the second order, the larger that of the first is.

By calculation, the optimal ordering quantity of the two orderings is $Q_{1}^{*}=79, Q_{2}^{*}=441$, the total optimal ordering quantity is $Q_{1}^{*}+Q_{2}^{*}=520$, and the optimal profit is $\pi_{r}^{*}=3352.31$. It can be seen that RFID technology improves the accuracy of demand forecasting and reduces the product loss rate. The optimal total ordering quantity is reduced compared with that without the RFID investment, while the optimal profit is increased.

When each parameter is changed, the influence of each parameter on the optimal ordering quantity and profit of the fresh retailer can be obtained, as shown in Tables 4 and 5 .

From lines 1 to 4 in Table 4, it can be found that the change of unit procurement $\operatorname{cost} w$, shortage cost $c_{s}$, disposal $\operatorname{cost} c_{d}$, and RFID cost $c_{r}$ does not affect the first optimal ordering quantity $Q_{1}^{*}$, which is consistent with the conclusion of Corollary 3 . However, their changes will affect the optimal total ordering quantity and profit. The increase of unit procurement cost $w$, disposal cost $c_{d}$, and RFID cost $c_{r}$ will reduce the total ordering quantity and profit, while the 
TABLE 2: The parameters' influence on the optimal ordering quantity and profit without RFID.

\begin{tabular}{lcccc}
\hline \multirow{2}{*}{ Parameters } & \multicolumn{3}{c}{ Relevant parameters increased by 30\% } \\
& Optimal ordering quantity $Q^{*}$ & Change rate of $Q^{*}(\%)$ & Optimal profit $\pi^{*}$ & Change rate of $\pi^{*}(\%)$ \\
\hline$c_{s}$ & 545 & 0.18 & 3333.34 & -0.08 \\
$w$ & 542 & -0.37 & 2847.20 & -14.65 \\
$c_{d}$ & 543 & -0.18 & 3333.48 & -0.08 \\
$\lambda$ & 555 & 2.02 & 3301.38 & -1.04 \\
$\mu$ & 705 & 29.60 & 4353.39 & 30.50 \\
$\sigma$ & 545 & 0.18 & 3328.27 & -0.23 \\
\hline
\end{tabular}

TABLE 3: Influence of lead time change on the optimal ordering quantity and profit without RFID.

\begin{tabular}{lcccc}
\hline$t$ (Day) & Optimal ordering quantity $Q^{*}$ & Change rate of $Q^{*}(\%)$ & Optimal profit $\pi^{*}$ & Change rate of $\pi^{*}(\%)$ \\
\hline 8 & 549 & 0.92 & 3319.61 & -0.49 \\
6 & 539 & -0.92 & 3352.25 & 0.49 \\
\hline
\end{tabular}

increase of unit shortage cost $c_{s}$ will increase the total ordering quantity and decrease profit. Meanwhile, by comparing lines 1 to 4 , it can also be found that unit procurement cost $w$ has a large influence on profit, while the other three parameters have a relatively small influence. See lines 5 and 6 ; it can be found that the increase of unit holding $c_{h}$ will lead to the decrease of the first optimal ordering quantity $Q_{1}^{*}$, while the increase of unit ordering delay cost $c_{b}$ will lead to the increase of $Q_{1}^{*}$, which is consistent with Corollary 5. And these two factors will not affect the total ordering quantity. However, the increase of them will lead to the decrease of the optimal profit. As can be seen from lines 7 to 9 , the increase of the product time dependence $\lambda$ will not cause the change of the first optimal ordering quantity, but will increase the optimal total ordering quantity and reduce the optimal profit. At the same time, the change of mean has a relatively large influence on the first optimal ordering quantity, the total ordering quantity, and the profit. While the variance does not affect the first and total ordering quantity, but only affects the profit, the influence degree is relatively small.

According to Table 5, we can see that the lengthening of the lead time $t_{r}$ will lead to an increase in the first and the total optimal ordering quantity and a decrease in the optimal profit. These are consistent with the conclusion of Corollaries 5 and 6 . While the second ordering arrival time $\tau$ will not affect the total optimal ordering quantity, it affects only the first optimal ordering quantity and profit, and the influence on the profit is very small.

4.3. Analysis of the Influence of RFID Investment on Fresh Retailer's Profit. According to the sensitivity and numerical analysis, it can be found that the influence of parameter changes in both models on the optimal total ordering quantity and profit has nothing to do with whether to invest in RFID or not. But the unit cost of RFID $c_{r}$ has direct influence on the optimal profit of fresh retailer. When the RFID input cost $c_{r}$ is higher than a certain value, the benefits brought by RFID, such as the reduction of loss rate, will be offset. At this time, the profit of the fresh retailer will be less than that without the RFID, and the retailer will not choose RFID investment $\pi$.
In this numerical example, when the unit RFID cost $c_{r}>0.13$, then $\pi_{r}<\pi$, as shown in Figure 3 . It means only when $c_{r}$ is less than 0.13 , the fresh retailer would like to invest in RFID.

At the same time, we can find that RFID technology can increase the fresh retailer's profit by shortening the lead time and reduce the time dependence of fresh product. However, whether the profit of the fresh retailer can be increased depends not only on the extent of the lead time shortening and time dependence reduction, but also on the unit RFID cost. If the unit RFID cost is too high, even if RFID technology can significantly shorten the lead time, it also will not increase the profit of fresh retailers. Here take $c_{r}=0.1$, $c_{r}=0.15, c_{r}=0.25$ as examples, shown in Figures 4 and 5 .

First, analyze the relationship between the lead time $t_{r}$ and profit under different RFID unit cost, as shown in Figure 4.

When the unit RFID cost is $c_{r}=0.1$, even if RFID technology only shortens the lead time by one day $\left(t_{r}=6\right), \pi_{r}$ is still greater than $\pi$. Moreover, with the increasing influence of RFID on the lead time, that is, the more the $t_{r}$ decreases, the more obvious the fresh retailer's profit increases, as shown in Figure 4(a). When $c_{r}=0.15$, the lead time $t_{r}$ needs to be reduced to 4 days, the profit of fresh retailer with RFID can be larger than that without RFID, as shown in Figure 4(b). When $c_{r}=0.25$, even if the lead time is reduced to 1 day $\left(t_{r}=1\right)$, $\pi_{r}$ is still less than $\pi$, as shown in Figure 4(c). At this point, no matter how much RFID shortens the lead time, the profit of fresh retailer with RFID is always less than without RFID.

The relationship between the time dependence $\lambda_{r}$ and profit under different RFID unit cost is similar, as shown in Figure 5.

When the unit RFID cost is $c_{r}=0.1$, even when $\lambda_{r}>0.05$, $\pi_{r}$ is still larger than $\pi$, as shown in Figure 5(a). This shows that when the unit RFID cost is very low, even if the time dependence of fresh product is not improved, the fresh retailer's profit can still be improved. At the same time, with the improvement of fresh products' time dependence, the profit of fresh retailer will also increase proportionately. 
TABLE 4: The parameters' influence on the optimal ordering quantity and profit without RFID.

\begin{tabular}{lcccccc}
\hline Parameters & \multicolumn{5}{c}{ Relevant parameters increased by 30\% } \\
& $\begin{array}{c}\text { First optimal ordering } \\
\text { quantity } Q_{1}^{*}\end{array}$ & $\begin{array}{c}\text { Change rate of } \\
Q_{1}^{*}(\%)\end{array}$ & $\begin{array}{c}\text { Total optimal ordering } \\
\text { quantity } Q_{1}^{*}+Q_{2}^{*}\end{array}$ & $\begin{array}{c}\text { Change rate of } \\
\left(Q_{1}^{*}+Q_{2}^{*}\right)(\%)\end{array}$ & $\begin{array}{c}\text { Optimal } \\
\text { profit } \pi_{r}^{*}\end{array}$ & $\begin{array}{c}\text { Change rate of } \\
\pi_{r}^{*}(\%)\end{array}$ \\
\hline$c_{s}$ & 79 & 0.00 & 521 & 0.19 & 3349.66 & -0.08 \\
$w$ & 79 & 0.00 & 519 & -0.19 & 2884.91 & -13.94 \\
$c_{d}$ & 79 & 0.00 & 519 & -0.19 & 3349.75 & -0.08 \\
$c_{r}$ & 79 & 0.00 & 519 & -0.19 & 3336.71 & -0.47 \\
$c_{h}$ & 78 & -1.27 & 520 & 0.00 & 3351.77 & -0.02 \\
$c_{b}$ & 80 & 1.27 & 520 & 0.00 & 3351.90 & -0.01 \\
$\lambda$ & 80 & 1.27 & 524 & 29.62 & 3340.17 & -0.36 \\
$\mu$ & 102 & 29.11 & 674 & 0.19 & 3343.54 & 30.46 \\
$\sigma$ & 79 & 0.00 & 521 & 0.23 \\
\hline
\end{tabular}

TABLE 5: Influence of lead time and second ordering arrival time with RFID.

\begin{tabular}{lcccccc}
\hline Parameters & $\begin{array}{c}\text { First optimal ordering } \\
\text { quantity } Q_{1}^{*}\end{array}$ & $\begin{array}{c}\text { Change rate of } \\
Q_{1}^{*}(\%)\end{array}$ & $\begin{array}{c}\text { Total optimal ordering } \\
\text { quantity } Q_{1}^{*}+Q_{2}^{*}\end{array}$ & $\begin{array}{c}\text { Change rate of }\left(Q_{1}^{*}+\right. \\
\left.Q_{2}^{*}\right)(\%)\end{array}$ & $\begin{array}{c}\text { Optimal } \\
\text { profit } \pi_{r}^{*}\end{array}$ & $\begin{array}{c}\text { Change rate of } \\
\pi_{r}^{*}(\%)\end{array}$ \\
\hline$t_{r}=6$ & 80 & 1.27 & 523 & 0.57 & 3344.23 \\
$t_{r}=4$ & 78 & -1.27 & 518 & -0.38 & 3360.35 \\
$\tau=4$ & 105 & 32.91 & 520 & 0.00 & 3351.97 \\
$\tau=2$ & 53 & -32.91 & 520 & 0.00 & 3352.68 \\
\hline
\end{tabular}

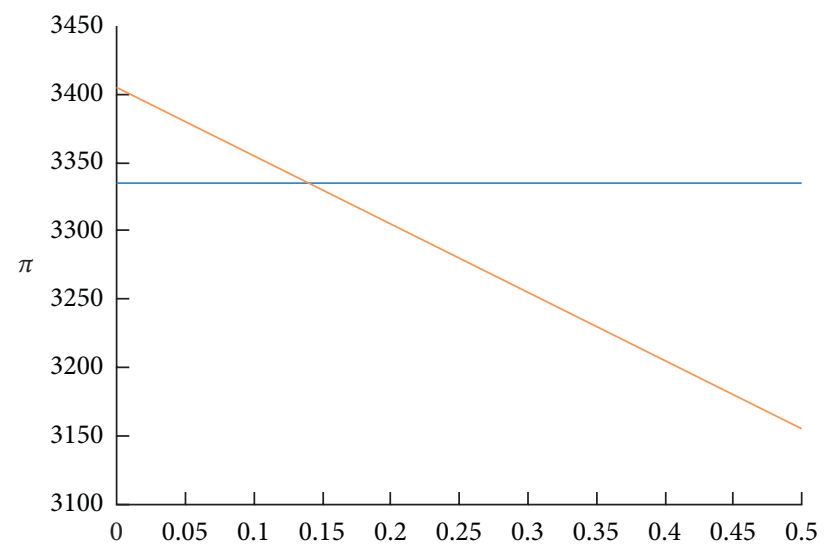

FIGURE 3: Influence of unit RFID cost on profit.

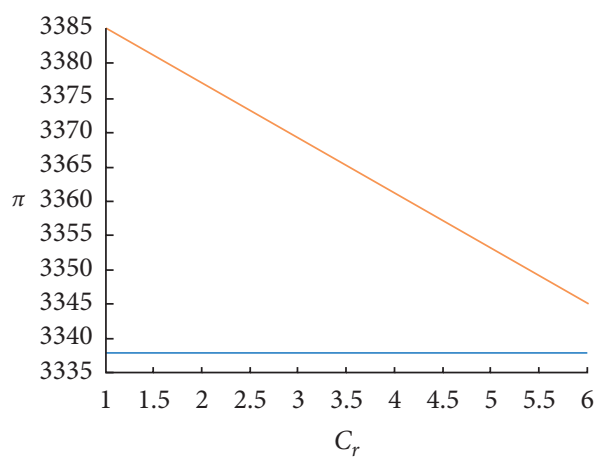

(a)

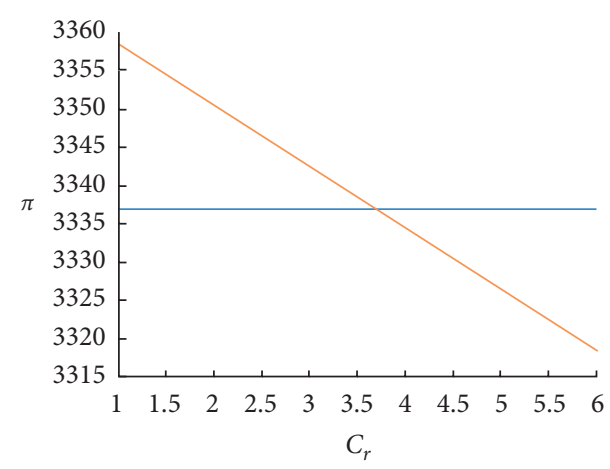

(b)

Figure 4: Continued. 


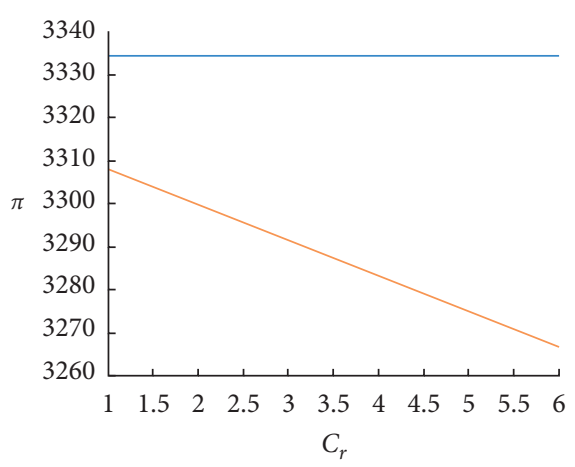

(c)

FIgURE 4: The relationship between the lead time $t_{r}$ and profit under different unit RFID cost. (a) $c_{r}=0.1$. (b) $c_{r}=0.15$. (c) $c_{r}=0.25$.

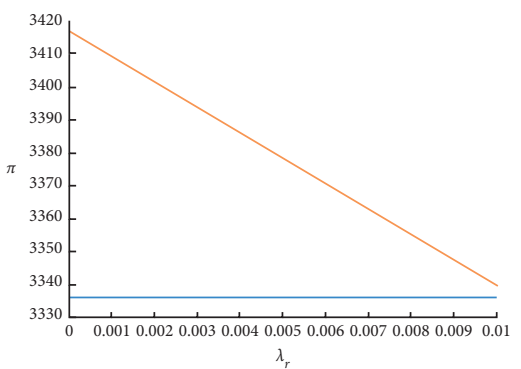

(a)

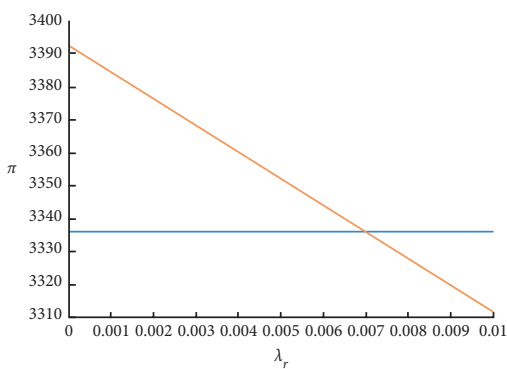

(b)

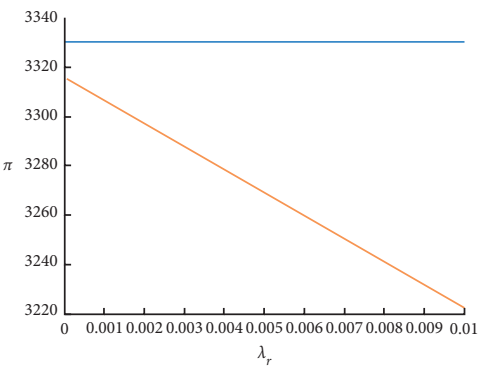

(c)

FIGURE 5: The relationship between the time dependence $\lambda_{r}$ and profit under different unit RFID cost. (a) $c_{r}=0.1$. (b) $c_{r}=0.15$. (c) $c_{r}=0.25$.

When $c_{r}=0.15, \quad \lambda_{r}>0.07, \quad \pi_{r}>\pi, \quad$ as shown in Figure 5(b). In other words, when $c_{r}=0.1$, in order to increase the fresh retailer's profit, the RFID technology must improve the time dependence of fresh product to less than 0.07 .

When $c_{r}=0.25$, even though RFID makes the fresh product no longer have time-dependence $\left(\lambda_{r}=0\right), \pi_{r}$ is less than $\pi$, as shown in Figure 5(c). That is, no matter how much RFID improves the time dependence of the fresh products, the profit of fresh retailer with RFID is always less than that without RFID.

\section{Conclusions}

According to the model analysis and numerical, the following conclusions can be obtained.

First, there is a unique optimal ordering quantity or ordering combination to maximize the profit of the fresh retailer with or without RFID investment.

Second, RFID investment does not change the influence of unit procurement cost, disposal cost, loss rate, lead time, and product time dependence on the optimal ordering quantity and optimal profit.

Third, only when the unit RFID cost is below a certain value, RFID investment will increase the profit of the fresh retailer. At this time, the fresh retailer should invest enough RFID; otherwise they should not invest in RFID.

Fourth, under RFID investment, the second-order time directly affects the profit of the fresh retailer. The later the second order time, the greater the profit of the fresh retailer. However, no matter when the second order is made, it will not change the optimal total ordering quantity.

The paper studies a two-level fresh product supply chain. Moreover, it only considers the behavior of retailer and does not consider the interaction of other participants in the supply chain. Further studies can focus more on a three-level supply chain and consider the interaction and cooperation between the participants in the supply chain. In addition, the study only considers the function of RFID to cut down the time and loss rate in transportation.

\section{Appendix}

\section{A. Proof 1}

Proposition A.1. Make a deformation equation (3); we can obtain 


$$
\pi=(p+c+s) \int_{0}^{\theta Q} x f(x) \mathrm{d} x-(p+c+s) \theta Q \int_{0}^{\theta Q} f(x) \mathrm{d} x+(p+s) \theta Q-s \mu-w Q
$$

Take the first and second derivatives of (A.1), respectively, and obtain

$$
\begin{aligned}
\frac{\partial \pi}{\partial Q} & =(p+s+c) \theta^{2} Q f(\theta Q)-(p+s+c) \theta^{2} Q f(\theta Q)-(p+s+c) \theta \int_{0}^{\theta Q} f(x) \mathrm{d} x+(p+s) \theta-w \\
& =-(p+s+c) \theta \int_{0}^{\theta Q} f(x) \mathrm{d} x+(p+s) \theta-w \\
\frac{\partial^{2} \pi}{\partial Q^{2}} & =-(p+s+c) \theta^{2} Q f(\theta Q)<0 .
\end{aligned}
$$

From (A.3), it can be known that $\pi$ is a convex function of $Q$; that is, there is a unique $Q^{*}$ so that itmaximizes $\pi$. Let $(\partial \pi / \partial Q)=0 ;(4)$ can be obtained:

$$
\int_{0}^{\theta Q^{*}} f(x) \mathrm{d} x=\frac{(p+s) \theta-w}{(p+s+c) \theta} .
$$

Proposition A.1 is proved.

\section{B. Proof 2}

Proposition B.1. Make a deformation equation (3); we can obtain

$$
\pi_{r}=(h+b) \int_{0}^{\theta_{r} Q_{1}} x_{1} f_{1}\left(x_{1}\right) \mathrm{d} x_{1}-(h+b) \theta_{r} Q_{1} \int_{0}^{\theta_{r} Q_{1}} f_{1}\left(x_{1}\right) \mathrm{d} x_{1}+(p+s) \theta_{r}\left(Q_{1}+Q_{2}\right)+b \theta_{r} Q_{1}-\left(b \mu_{1}+s \mu\right)-\left(w+c_{r}\right)\left(Q_{1}+Q_{2}\right) .
$$

Take the first derivative of (B.1) with respect to $Q_{1}$ and $Q_{2}$ and obtain

$$
\begin{aligned}
& \frac{\partial \pi_{r}}{\partial Q_{1}}=-(p+s+c) \int_{0}^{\theta_{r}\left(Q_{1}+Q_{2}\right)} f(x) \mathrm{d} x-(h+b) \theta_{r} \int_{0}^{\theta_{r} Q_{1}} f_{1}\left(x_{1}\right) \mathrm{d} x_{1}+(p+s) \theta_{r}+b \theta_{r}-\left(w+c_{r}\right) \\
& \frac{\partial \pi_{r}}{\partial Q_{2}}=-(p+s+c) \int_{0}^{\theta_{r}\left(Q_{1}+Q_{2}\right)} f(x) \mathrm{d} x+(p+s) \theta_{r}-\left(w+c_{r}\right) .
\end{aligned}
$$

Take the second derivative of (B.2) and (B.3) with respect to $Q_{1}$ and $Q_{2}$ and obtain

$$
\begin{aligned}
\frac{\partial^{2} \pi_{r}}{\partial Q_{1}^{2}} & =-(p+s+c) \theta_{r}^{2} f\left(\theta_{r}\left(Q_{1}+Q_{2}\right)\right)-(h+b) \theta_{r}^{2} Q_{1} f_{1}\left(\theta_{r} Q_{1}\right)<0, \\
\frac{\partial^{2} \pi_{r}}{\partial Q_{2}^{2}} & =-(p+s+c) \theta_{r}^{2} f\left(\theta_{r}\left(Q_{1}+Q_{2}\right)\right)<0, \\
\frac{\partial^{2} \pi_{r}}{\partial Q_{1} \partial Q_{2}} & =\frac{\partial^{2} \pi_{r}}{\partial Q_{2} \partial Q_{1}}=-(p+s+c) \theta_{r}^{2} f\left(\theta_{r}\left(Q_{1}+Q_{2}\right)\right)<0 .
\end{aligned}
$$


And

$$
\frac{\partial^{2} \pi_{r}}{\partial Q_{1}^{2}} \frac{\partial^{2} \pi_{r}}{\partial Q_{2}^{2}}-\left(\frac{\partial^{2} \pi_{r}}{\partial Q_{1} \partial Q_{2}}\right)^{2}=(p+s+c) \theta_{r}^{2} f\left(\theta_{r}\left(Q_{1}+Q_{2}\right)\right) *(h+b) \theta_{r}^{2} Q_{1} f_{1}\left(\theta_{r} Q_{1}\right)>0 .
$$

Therefore, $\pi_{r}$ is a convex function of $\left(Q_{1}+Q_{2}\right)$, so there is a single optimal combination of order quantities $\left(Q_{1}^{*}, Q_{2}^{*}\right)$ that maximized the profit of fresh retailer.

Let $\left(\partial \pi_{r} / \partial Q_{1}\right)=0$ and $\left(\partial \pi_{r} / \partial Q_{2}\right)=0$; (7) and (8) can be obtained.

Proposition B.1 is proved.

\section{Data Availability}

The research method of this paper is mathematical model derivation, and numerical examples are used for verification. Data are available upon request to the corresponding author.

\section{Conflicts of Interest}

The author declares no conflicts of interest.

\section{Acknowledgments}

This research was supported by the Tianjin Philosophy and Social Science Planning Project "Research on Agricultural IoT Investment and Government Subsidy under the Background of Beijing-Tianjin-Hebei Collaborative Development" (Grant number: TJGL17-021).

\section{References}

[1] R. Montanari, "Cold chain tracking: a managerial perspective," Trends in Food Science \& Technology, vol. 19, no. 8, pp. 425-431, 2008.

[2] N. Fu, X. Zhang, and Z. Jia, "Game analysis on government subsidy for agricultural enterprise' IoT investment," IOP Conference Series Materials Science and Engineering, vol. 688, Article ID 055040, 2019.

[3] F. Wu and J. Ma, "Evolution dynamics of agricultural internet of things technology promotion and adoption in China," Discrete Dynamics in Nature and Society, vol. 2020, Article ID 1854193, 18 pages, 2020.

[4] I. Brown and J. Russell, "Radio frequency identification technology: an exploratory study on adoption in the South African retail sector," International Journal of Information Management, vol. 27, no. 4, pp. 250-265, 2007.

[5] C. Costa, F. Antonucci, F. Pallottino, J. Aguzzi, D. Sarriá, and P. Menesatti, "A review on agri-food supply chain traceability by means of RFID technology," Food and Bioprocess Technology, vol. 6, no. 2, pp. 353-366, 2013.

[6] H. Gurnani and C. S. Tang, "Note: optimal ordering decisions with uncertain cost and demand forecast updating," Management Science, vol. 45, no. 10, pp. 1456-1462, 1999.

[7] H. Yan, H. Zhang, S. Sethi, and J. Zhou, "A supply chain with a service requirement for each market signal," Production \& Operations Management, vol. 16, no. 3, pp. 322-342, 2010.
[8] L. Ma, Y. Zhao, W. Xue, T. C. E. Cheng, and H. Yan, "Lossaverse newsvendor model with two ordering opportunities and market information updating," International Journal of Production Economics, vol. 140, no. 2, pp. 912-921, 2012.

[9] J. Li, S. Chand, M. Dada, and S. Mehta, "Managing inventory over a short season: models with two procurement opportunities," Manufacturing \& Service Operations Management, vol. 11, no. 1, pp. 174-184, 2016.

[10] M. Khouja and J. Zhou, "An off-price retailer with two ordering opportunities and demand updating," International Journal of Production Economics, vol. 188, no. 6, pp. 128-138, 2017.

[11] A. Herbon, M. Shnaiderman, and T. Chernonog, "Postponed two-pricing and ordering opportunity for selling a single season inventoried product," Annals of Operations Research, vol. 271, no. 2, pp. 619-640, 2018.

[12] D. Tiwari, R. Patil, and J. Shah, "Unreliable newsboy problem with a forecast update," Operations Research Letters, vol. 39, no. 4, pp. 278-282, 2011.

[13] Y.-W. Zhou and S.-D. Wang, "Supply chain coordination for newsvendor-type products with two ordering opportunities and demand information update," Journal of the Operational Research Society, vol. 63, no. 12, pp. 1655-1678, 2012.

[14] T. Wang, A. Atasu, and M. Kurtuluş, "A multiordering newsvendor model with dynamic forecast evolution," Manufacturing \& Service Operations Management, vol. 14, no. 3, pp. 472-484, 2012.

[15] A. Jain, K. Moinzadeh, and Y.-P. Zhou, "A single-supplier, multiple-retailer model with single-season, multiple-ordering opportunities, and fixed ordering cost," Operations Research, vol. 60, no. 5, pp. 1098-1110, 2012.

[16] H. M. Wee and W. T. Wang, "Supply chain coordination for short-life-cycle products with option contract and partial backorders," European J. of Industrial Engineering, vol. 7, no. 1, pp. 78-99, 2013.

[17] X. Kelei, X. Ya, and F. Lipan, "Managing procurement for a firm with two ordering opportunities under dupply disruption Risk," Sustainability, vol. 10, no. 9, Article ID 3293, 2018.

[18] J. Ma and Z. Guo, "The parameter basin and complex of dynamic game with estimation and two-stage consideration," Applied Mathematics and Computation, vol. 248, pp. 131-142, 2014.

[19] J. Ma and H. Wang, "Complexity analysis of dynamic noncooperative game models for closed-loop supply chain with product recovery," Applied Mathematical Modelling, vol. 38, no. 23, pp. 5562-5572, 2014.

[20] J. Ma and F. Wu, "The application and complexity analysis about a high-dimension discrete dynamical system based on heterogeneous triopoly game with multi-product," Nonlinear Dynamics, vol. 77, no. 3, pp. 781-792, 2014.

[21] F. Wu and J. Ma, "The complex dynamics of a multi-product mixed duopoly model with partial privatization and crossownership," Nonlinear Dynamics, vol. 80, no. 3, pp. 1391-1401, 2015. 
[22] A. Naimzada and F. Tramontana, "Two different routes to complex dynamics in an heterogeneous triopoly game," Journal of Difference Equations and Applications, vol. 21, no. 7, pp. 553-563, 2015.

[23] J. Ma and L. Xie, "The comparison and complex analysis on dual-channel supply chain under different channel power structures and uncertain demand," Nonlinear Dynamics, vol. 83, no. 3, pp. 1379-1393, 2016.

[24] J. Ma and R. Hao, "Influence of government regulation on the stability of dual-channel recycling model based on customer expectation," Nonlinear Dynamics, vol. 94, no. 3, pp. 1775-1790, 2018.

[25] C. H. Hommes, M. I. Ochea, and J. Tuinstra, "Evolutionary competition between adjustment processes in cournot oligopoly: instability and complex dynamics," Dynamic Games and Applications, vol. 8, no. 4, pp. 822-843, 2018.

[26] F. Wu and J. Ma, "The equilibrium, complexity analysis and control in epiphytic supply chain with product horizontal diversification," Nonlinear Dynamics, vol. 93, no. 4, pp. 2145-2158, 2018.

[27] N. Ahmad and P. Marina, "Complex dynamics in an evolutionary general equilibrium model," Discrete Dynamics in Nature \& Society, vol. 2018, Article ID 8471624, 13 pages, 2018.

[28] S. S. Askar, M. F. El-Wakeel, and M. A. Alrodaini, "Exploration of complex dynamics for cournot oligopoly game with differentiated products," Complexity, vol. 2018, Article ID 6526794, 13 pages, 2018.

[29] W. Lou and J. Ma, "Complexity of sales effort and carbon emission reduction effort in a two-parallel household appliance supply chain model," Applied Mathematical Modelling, vol. 64, pp. 398-425, 2018.

[30] J. Ma and L. Sun, "Complexity analysis about nonlinear mixed oligopolies game based on production cooperation," IEEE Transactions on Control Systems Technology, vol. 26, no. 4, pp. 1532-1539, 2018.

[31] B. Bao, J. Ma, and M. Goh, "Short- and long-term repeated game behaviours of two parallel supply chains based on government subsidy in the vehicle market," International Journal of Production Research, vol. 58, no. 24, pp. 7507-7530, 2020.

[32] J. Ma, Y. Hou, Z. Wang, and W. Yang, "Pricing strategy and coordination of automobile manufacturers based on government intervention and carbon emission reduction," Energy Policy, vol. 148, Article ID 111919, 2021.

[33] Y. Peng, Q. Lu, W. Xue, Y. Zhao, and Y. Xiao, "Dynamics of Hotelling triopoly model with bounded rationality," Applied Mathematics and Computation, vol. 373, Article ID 125027, 2020.

[34] W. Zhou and X.-X. Wang, "On the stability and multistability in a duopoly game with R\&D spillover and price competition," Discrete Dynamics in Nature and Society, vol. 2019, Article ID 2369898, 20 pages, 2019.

[35] J. Ma, Y. Hou, W. Yang, and Y. Tian, “A time-based pricing game in a competitive vehicle market regarding the intervention of carbon emission reduction," Energy Policy, vol. 142, Article ID 111440, 2020.

[36] L. Xie, J. Ma, and M. Goh, "Supply chain coordination in the presence of uncertain yield and demand," International Journal of Production Research, vol. 3, pp. 1-17, 2020.

[37] H. Garmani, A. O. Driss, E. A. Mohamed, B. Mohamed, and J. Mostafa, "Analysis of a dynamics duopoly game with two content providers," Chaos Solitons \& Fractals, vol. 131, Article ID 109466, 2020.
[38] T. Xu and J. Ma, "Feed-in tariff or tax-rebate regulation? Dynamic decision model for the solar photovoltaic supply chain," Applied Mathematical Modelling, vol. 89, no. 2, pp. 1106-1123, 2020.

[39] J. G. Szmerekovsky and J. Zhang, "Coordination and adoption of item-level RFID with vendor managed inventory," International Journal of Production Economics, vol. 114, no. 1, pp. 388-398, 2008.

[40] S. Goyal, B. C. Hardgrave, J. Aloysius, and N. D. Horatius, "Measuring the impact of RFID on out of stocks at WalMart," MIS Quarterly Executive, vol. 7, no. 4, 2008.

[41] B. C. Hardgrave, J. A. Aloysius, and S. Goyal, "RFID-enabled visibility and retail inventory record inaccuracy: experiments in the field," Production and Operations Management, vol. 22, no. 4, pp. 843-856, 2013.

[42] Y. Rekik, E. Sahin, and Y. Dallery, "Inventory inaccuracy in retail stores due to theft: an analysis of the benefits of RFID," International Journal of Production Economics, vol. 118, no. 1, pp. 189-198, 2009.

[43] H. S. Heese, "Inventory record inaccuracy, double marginalization, and RFID adoption," Production \& Operations Management, vol. 16, no. 5, pp. 542-553, 2010.

[44] A. Z. Camdereli and J. M. Swaminathan, "Misplaced inventory and radio-frequency identification (RFID) technology: information and coordination," Production and Operations Management, vol. 19, no. 1, pp. 1-18, 2010.

[45] B. Yan, S. Shi, B. Ye, X. Zhou, and P. Shi, "Sustainable development of the fresh agricultural products supply chain through the application of RFID technology," Information Technology and Management, vol. 16, no. 1, pp. 67-78, 2015.

[46] I.-H. Hong, J.-F. Dang, Y.-H. Tsai et al., "An RFID application in the food supply chain: a case study of convenience stores in Taiwan," Journal of Food Engineering, vol. 106, no. 2, pp. 119-126, 2011.

[47] L. Ruiz-Garcia and L. Lunadei, "The role of RFID in agriculture: applications, limitations and challenges," Computers and Electronics in Agriculture, vol. 79, no. 1, pp. 42-50, 2011.

[48] L. Kumari, K. Narsaiah, M. K. Grewal, and R. K. Anurag, "Application of RFID in agri-food sector," Trends in Food Science \& Technology, vol. 43, no. 2, pp. 144-161, 2015.

[49] G. M. Gaukler, R. W. Seifert, and W. H. Hausman, "Item-level RFID in the retail supply chain," Production \& Operations Management, vol. 16, no. 1, pp. 65-76, 2010.

[50] B. Yan, X. Chen, Q. Yuan, and X. Zhou, "Sustainability in fresh agricultural product supply chain based on radio frequency identification under an emergency," Central European Journal of Operations Research, vol. 28, no. 2, pp. 1343-1361, 2020.

[51] Y. Li, S. Deng, Y. Zhang, and B. Liu, "Coordinating the retail supply chain with item-level RFID and excess inventory under a revenue-cost-sharing contract," International Transactions in Operational Research, vol. 28, no. 3, pp. 1505-1525, 2021. 